\title{
THE POLAROGRAPHIC DETERMINATION OF STABILITY CONSTANTS OF UREA/CROWN ETHER COMPLEXES IN METHANOL
}

\author{
D. PH. ZOLLINGER, M. BOS, A. M. W. VAN VEEN-BLAAUW \\ and W. E. VAN DER LINDEN* \\ Department of Chemical Technology, Twente University of Technology, Enschede \\ (The Netherlands)
}

(Received 13th February 1984)

\section{SUMMARY}

A general method for determination of the stability constants of complexes of crown ethers and related compounds with small organic molecules in polar solvents is described, based on an indirect polarographic procedure. Computerized evaluation of the data forms an essential part of the procedure.

Since the publication of the pioneering paper of Pedersen in 1967 [1], interest in the chemistry of crown ethers and related compounds has steadily increased, not only from a purely scientific point of view, but also with regard to possible applications of crown ethers in (organic) synthesis, analytical chemistry and in the field of physiological processes and pharmacology $[2,3]$.

Apart from the abundance of data on complexes of various crown ethers with metal ions and other cations that can be found in the literature, complexes with neutral molecules are also mentioned [4]. Complexation of (uncharged) molecules plays an essential role in many biological processes such as enzyme-substrate and pharmacon-receptor interactions. In this respect, the study of the interactions between crown ethers and neutral molecules could eventually lead to the design of specific host molecules for compounds of biological significance like neurotransmitters, drugs and toxic compounds.

For a number of complexes of crown ethers with neutral molecules, the crystal structure has been elucidated (Table 1), but crystalline complexes for which the crystalline structure has not yet been resolved have been reported for many other compounds [4]. In this Department, interest in these neutral compound complexes was aroused during consideration of the possibility of using crown ethers in the selective removal of urea from dialysis fluid, one of the major problems in the current practice of kidney dialysis.

In order to obtain guidelines for the synthesis of possible urea-selective crown-type ligands, it was necessary to have information concerning the 
TABLE 1

Crystalline complexes of crown ethers with neutral compounds

\begin{tabular}{lllr}
\hline Host & Guest & Stoichiometry & Ref. \\
\hline 18C6 & Dimethylacetylenedicarboxylate & $1: 1$ & {$[5]$} \\
18C6 & Benzenesulfonamide & $1: 2$ & {$[6]$} \\
$18 C 6$ & Malononitrile & $1: 2$ & {$[7]$} \\
$18 C 6$ & Urea & $1: 5^{\mathrm{a}}$ & {$[8]$} \\
18C6 & bis-Dimethylsulfone & $1: 2$ & {$[9]$} \\
18C6 & Guanidiniumnitrate & $1: 2$ & {$[10]$} \\
18C6 & S-t-Butylthiouronium perchlorate & $1: 2$ & {$[11]$} \\
18C6 & Uronium nitrate & $1: 1$ & {$[12]$} \\
B27C9 & Uronium perchlorate & $1: 1$ & {$[12]$} \\
B27C9 & Guanidinium perchlorate & $1: 1$ & {$[13]$} \\
18C6 & Nitromethane & $1: 2$ & {$[14]$} \\
DB18C6 & t-Butylammonium perchlorate/DDQ & $1: 1: 1$ & {$[15]$} \\
DB27C9 & Guanidinium perchlorate & $1: 1$ & {$[16]$} \\
DB30C10 & Guanidinium perchlorate & $1: 1$ & {$[16]$} \\
\hline
\end{tabular}

a Only two urea molecules are hydrogen-bonded to both sides of the 18-crown-6 molecule; the remaining molecules form hydrogen-bonded layers.

degree of binding of urea by these ligands; in other words, to determine the stoichiometry and the corresponding stability constants of the complexes between these compounds. The aim was to develop suitable methods for this purpose, and the study was limited to polar solvents in view of the use of the compounds to be synthesized in biomedical applications where aqueous systems are involved.

A large number of techniques and methods is available for the determination of stability constants and many of these have been used in studies of the complexation of metal ions by crown ethers; for example, potentiometry, conductometry, polarography/voltammetry, calorimetry, n.m.r. spectroscopy, liquid-liquid extraction methods and osmometry have been applied [17]. Among the factors that determine the choice of technique and method appropriate for a certain problem are the physicochemical properties of the compounds of interest, the solvent to be used and the availability of instrumentation.

In the problem given, two classes of compounds must be considered: crown ethers and related compounds on one side and small organic molecules like urea, acetonitrile, malonitrile and nitromethane on the other side. The physicochemical properties of urea and similar compounds and of crown ethers that carry no chromophoric substituents do not allow the application of u.v.-visible spectrophotometry; also potentiometry, another technique often used in complexation studies, is not applicable as such. The use of aqueous systems and the need for a high degree of automation eliminate some other techniques, such as osmometry. Therefore, attention was focussed on the development of an electrochemical method, particularly polarography. 


\section{THEORY}

As the system of particular interest (urea/crown ether complexes) does not contain any compounds that can be reduced and/or oxidized at the DME under normal conditions, it is necessary to add an auxiliary compound that forms complexes with one or both of the components present and that can be determined polarographically. (This approach was originally described by Schwarzenbach and Ackermann [18] and by Ringbom and Eriksson [19] for stable 1:1 complexes and stepwise complex formation, respectively).

In view of the characteristic properties of crown ethers and related compounds, the use of an alkali metal ion for this purpose seemed to be an obvious choice. The equilibria in solution, assuming 1:1 complexation and neglecting solvation are

$\mathrm{M}+\mathrm{CE} \rightleftarrows(\mathrm{MCE}) ; \quad$ Urea $+\mathrm{CE} \rightleftarrows($ urea-CE)

where $\mathrm{M}$ denotes the metal ion and $\mathrm{CE}$ is the crown compound.

The polarographic determination of stability constants is nowadays generally based on the method of DeFord et al. $[20,21]$ or a modification of it. For the reversible reduction of a metal ion in the presence of an excess of the ligand, the cathodic displacement of the half-wave potential and the change in limiting current value as a function of the (free) ligand concentration are used to determine the consecutive stability constants $K_{1} \ldots K_{n}$

$\mathrm{M}+\mathrm{L} \rightleftarrows \mathrm{ML} ; \mathrm{ML}+\mathrm{L} \rightleftharpoons \mathrm{ML}_{2} ; \ldots ; \mathrm{ML}_{n-1}+\mathrm{L} \rightleftharpoons \mathrm{ML}_{n}$

with $K_{n}=\left[\mathrm{ML}_{n}\right] /\left[\mathrm{ML}_{n-1}\right][\mathrm{L}]$ and $\beta_{n}=\left[\mathrm{ML}_{n}\right] /[\mathrm{M}][\mathrm{L}]^{n}$ (L is the ligand, $K_{l}$ the stability constant for the $i$ th complex and $\beta_{\imath}$ the overall stability constant for the $i$ th complex).

In a medium of constant ionic strength, a formation function $F_{0}$ can be defined as

$F_{0}=C_{\mathrm{M}} /[\mathrm{M}]=\beta_{0}+\beta_{1}[\mathrm{~L}]+\ldots \ldots+\beta_{n}[\mathrm{~L}]^{n}$,

$C_{\mathrm{M}}$ and $[\mathrm{M}]$ representing the analytical and free metal concentrations, respectively. $F_{0}$ can also be expressed as a function of experimental parameters:

$F_{0}=\exp \left[(n F / R T)\left(E_{\mathrm{s}}^{1 / 2}-E_{\mathrm{c}}^{1 / 2}\right)+\ln \left(I_{\mathrm{s}}^{\mathrm{d}} / I_{\mathrm{c}}^{\mathrm{d}}\right)\right]$

The subscripts $c$ and $s$ denote the cases for complexation and no complexation, respectively, and the other symbols have their usual meaning. Further functions $F_{l}$ can be derived from the preceding formation functions $F_{1-1}$ and the corresponding value of the stahility constants $\beta_{t-1}$ :

$F_{l}=\left(F_{i-1}-\beta_{i-1}\right) /[\mathrm{L}]$,

where $[\mathrm{L}]$ is the free ligand concentration of the solution.

From these formation functions $F_{i}$, the number of complexes present and their stability constants $\beta_{l}$ can be found by means of graphical analysis as well as by (computerized) mathematical processing of the data. The latter 
approach certainly is to be preferred, especially because powerful and cheap (micro)computers are available in many laboratories. (Nevertheless, Gaizer [22] as well as Rossotti et al. [23] in their reviews on computerized evaluation of complex equilibria, stress the importance of using graphical analysis alongside the computer method and point out the danger of relying exclusively on the outcome of the calculations).

\section{COMPUTER PROGRAM}

The automation of the polarographic determination of stability constants is almost a necessity in order to obtain reliable and precise results $[24,25]$. Besides, (computerized) statistical evaluation of the data provides a means of calculating the errors of the parameters sought.

The DeFord-Hume method has been computerized by several authors [26-30]; all these programs are based on a form of least-squares analysis. The Legget method (POLAG [30]) is the most general in approach and uses well-known procedures, as it is based on earlier programs for the calculation of stability constants (SQUAD) [31] and SCOGS [32]).

The least-squares approach is aimed at minimizing $U$, the sum of the residuals

$U=\sum_{1}^{N} w_{l}\left(F_{\mathrm{obs}}-F_{\mathrm{calc}}\right)^{2}$,

where $N$ denotes the number of data points and $w_{l}$ is the weighting factor (which is set to one in the POLAG program); $F_{\text {obs }}$ is obtained from the experimentally found parameters using Eqn. 4 and $F_{\text {calc }}$ is calculated from Eqn. 3.

As a first step in the automation of the procedure for the system described, the POLAG program was edited for the 2 metals +1 ligand model used. The MAIN part of the program was adapted in order to be able to use the program for experiments with variable metal concentrations, an option not available in the original program. Further, the data input was modified so that it could be checked before the actual start of the refinement procedures.

\section{EXPERIMENTAL}

\section{Chemicals and apparatus}

Tetramethylammonium chloride (Merck, zur Synthese) and tetraethylammonium chloride (Fluka, purum) were recrystallized from water or from water and ethanol, depending on the solvent used.

Benzo-15-crown-5 and dibenzo-24-crown-8 (Merck) were used without further purification. Benzo-27-crown-9 was synthesized in the Department of Organic Chemistry of this University and was used as received. 
18-Crown-6 (Merck) was purified from the acetonitrile complex as described by Gold and Rice [33].

Double-distilled water was used throughout the experiments and all other chemicals were at least of analytical-reagent grade.

A Metrohm Polarecord E506 in conjunction with the E505 polarographic stand was used, operating in the 3 -electrode mode. The auxiliary electrode was a platinum wire and a laboratory-made silver/silver chloride electrode served as reference electrode. Glass capillaries (Metrohm) were used as obtained.

\section{Polarographic procedure and data evaluation}

Purified nitrogen was led over heated copper $\left(350^{\circ} \mathrm{C}\right)$ and pre-saturated with the solvent used before it was led through the solutions to remove oxygen. The polarographic cell was kept at $25.0 \pm 0.1^{\circ} \mathrm{C}$.

Concentrated solutions of crown ethers and urea were added stepwise to solutions containing the alkali metal salts by means of a burette. After each addition, nitrogen was bubbled through for another $3 \mathrm{~min}$ and the polarogram was recorded.

The polarograph was operated in the d.c.-Tast mode with the drop time set to $0.8 \mathrm{~s}$; the scan speed was 2.5 or $5 \mathrm{mV} \mathrm{s}^{-1}$.

From a series of current-potential data pairs, the limiting current values and halfwave potentials were calculated from the d.c. polarograms by means of a 3-parameter curve-fitting procedure based on least-squares [34]. The results of these calculations were used as the input values for the modified POLAG program from which the stability constants and their standard deviations were obtained.

\section{RESULTS AND DISCUSSION}

In order to test the procedure described and the modification of the computer program, an experiment was done in which potassium ion competed with thallium(I) ion for 18-crown-6 in aqueous solution. Complexation of $\mathrm{Tl}^{+}$by 18-crown- 6 was reflected by a small cathodic shift of the halfwave potential and by a decrease in the limiting current value for the reduction wave of the thallium ion. Upon addition of the potassium ion, a reversed effect was observed, indicating a replacement of $\mathrm{Tl}^{+}$by $\mathrm{K}^{+}$in the cavity of the crown ether. The results, summarized in Table 2, show that the method can be used for the indirect determination of stability constants of crown ether complexes.

In the search for an appropriate indicator system, the first point studied was the influence of the composition of the solvent with regard to the water content on the stability constant of the potassium/18-crown-6 complex (Table 3). As expected, an increase in water content lowers the stability of the complex, which can be regarded as the effect of an increase in dielectric constant of the solvent. 


\section{TABLE 2}

Competition between $\mathrm{Tl}^{+}$and $\mathrm{K}^{+}$for 18-crown-6 in $0.1 \mathrm{M}$ tetramethylammonium hydroxide in water, at $25.0^{\circ} \mathrm{C}$

\begin{tabular}{|c|c|c|c|c|c|}
\hline & & $\log K$ & $s, d^{a}$ & Lit. value & Ref. \\
\hline Direct & $\mathrm{Tl}^{+}$ & 2.3 & 0.1 & 2.27 & [35] \\
\hline Indirect & $\mathbf{K}^{+}$ & 2.1 & 0.1 & 2.06 & {$[36]$} \\
\hline
\end{tabular}

a The standard deviation of the stability constant was calculated from the data set of a single experiment.

\section{TABLE 3}

Influence of water content on the stability constant of the potassium/18-crown-6 complex (electrolyte, $0.1 \mathrm{M}$ tetramethylammonium hydroxide; temperature $20.0^{\circ} \mathrm{C}$; solvent, isopropanol(IPA)/methanol(MeOH)/water)

\begin{tabular}{clllll}
\hline IPA-MeOH $(3: 1)$ & Water & $\log K^{\mathrm{a}}$ & IPA-MeOH $(3: 1)$ & Water & \multicolumn{1}{l}{$\log K^{\mathrm{a}}$} \\
\hline 10 & 0 & $7.3 \pm 0.36$ & 6 & 4 & $3.48 \pm 0.06$ \\
9 & 1 & $5.23 \pm 0.06$ & 5 & 5 & $3.04 \pm 0.04$ \\
8 & 2 & $4.38 \pm 0.05$ & 3 & 7 & $2.79 \pm 0.02$ \\
7 & 3 & $4.02 \pm 0.06$ & 0 & 10 & $2.32 \pm 0.15$ \\
\hline
\end{tabular}

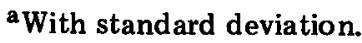

When potassium was used as the indicator ion in water/methanol mixtures (water content $30-70 \%$ ), it was not possible to determine the stability constant of the urea/18-crown-6 complex in these solutions: no shift in halfwave potential and/or limiting current could be observed upon addition of urea. Apparently, the interaction between urea and 18-crown-6 under the conditions used is too weak to be studied in this way.

As the reduction of the potassium complex of 18-crown-6 in these solvents gave rise to rather unfavorably defined polarographic waves, potassium was replaced by rubidium which is reduced at a slightly more positive potential and has comparable properties towards crown ethers. Methanol was used as solvent in the first studies of 18-crown-6 complexes. In this case, addition of urea to a solution of the metal/crown complex produced a change in the reduction wave characteristics, but the effects observed were very small. The stability constants found for the urea-complex varied from 0.2 to 0.7 with a standard deviation for the individual determinations of 0.15 to 0.20 .

From x-ray crystal structure data, it can be seen [9] that the ring of the 18-crown-6 molecule is too small to envelop the urea molecule and that larger rings are necessary for this purpose [11-13]. Therefore, three other crown ethers were used to study the influence of the ring size upon complexation of urea in competition with the rubidium ion (Table 4).

For benzo-15-crown-5, no convergence of the computer calculations was 


\section{TABLE 4}

Stability constants of rubidium complexes in methanol and of urea complexes with rubidium as the indicator ion (temperature $25.0^{\circ} \mathrm{C}$; electrolyte, $0.1 \mathrm{M}$ tetraethylammonium iodide)

\begin{tabular}{llllll}
\hline Crown & \multicolumn{2}{l}{ Rb complex } & & \multicolumn{2}{l}{ Urea complex } \\
\cline { 2 - 3 } & log $K$ & s.d. & & $\log K$ & s.d. \\
\hline Benzo-15-crown-5 & 3.11 & 0.05 & - a & \\
18-crown-6 & 5.47 & 0.04 & $-\mathrm{b}$ & 0.1 \\
Dibenzo-24-crown-8 & 3.76 & 0.03 & 1.1 & 0.1 \\
Benzo-27-crown-9 & 3.78 & 0.03 & 1.2 & 0 \\
\hline
\end{tabular}

a No convergence. ${ }^{b}$ No reproducible value: $\log K$ varied from 0.2 to 0.7 with s.d. 0.15 to 0.20 .

obtained at all, indicating no complexation of urea. For the two benzo-substituted crown ethers with larger rings (dibenzo-24-crown-8 and benzo-27crown-9), the values of the stability constants were small. This demonstrates that the cavity size of these crown ethers is better suited for the urea molecule than the smaller cavity of 18-crown-6.

The approach described is considered to provide a suitable method for obtaining information about the complexation of small organic molecules such as urea in polar solvents. However, improvement of the precision of the data obtained is necessary in order to gain more insight into the physicochemical parameters that determine the stability of the complexes involved. This can be achieved by further automation of the procedure described, which will be the subject of a forthcoming paper.

The authors thank Dr. D. J. Leggett (Dow Chemical USA, Freeport, TX) for providing them with a listing of the computer program POLAG, J. Geevers (Department of Organic Chemistry, Twente University of Technology) for the synthesis and purification of benzo-27-crown-9 and Mrs. B. Verbeeten-van Hettema for preparing the manuscript. These investigations were supported (in part) by the Netherlands Foundation for Technical Research (STW), future Technical Science Branch/Division of the Netherlands Organization for the Advancement of Pure Research (ZWO).

\section{REFERENCES}

1 C. J. Pedersen, J. Am. Chem. Soc., 89 (1967) 7017.

2 F. de Jong and D. N. Reinhoudt, Adv. Phys. Org. Chem., 17 (1980) 279.

3 E. Weber and F. Vögtle, Top. Curr. Chem., 98 (1981) 1.

4 F. Vögtle, H. Sieger and W. H. Müller, Top. Curr. Chem., 98 (1981) 107.

5 I. Goldberg, Acta Crystallogr., 31B (1975) 754.

6 A. Knöchel, J. Kopf, J. Oehler and G. Rudolph, J. Chem. Soc., Chem. Commun., (1978) 595. 
7 R. Kaufman, A. Knöchel, J. Kopf, J. Oehler and G. Rudolph, Chem. Ber., 110 (1977) 2249.

8 S. Harkema, G. J. van Hummel, K. Daasvatn and D. N. Reinhoudt, J. Chem. Soc., Chem. Commun., (1981) 368.

9 J. A. Bandy, M. R. Truter and F. Vögtle, Acta Crystallogr., 37B (1981) 1568.

10 J. A. Bandy, M. R. Truter and J. N. Wingfield, J. Chem. Soc., Perkin Trans. 2, (1981) 1025.

11 J. W. H. M. Uiterwijk, S. Harkema, G. J. van Hummel, J. Geevers and D. N. Reinhoudt, Acta Crystallogr., 38B (1982) 1862.

12 J. W. H. M. Uiterwijk, S. Harkema, D. N. Reinhoudt, K. Daasvatn, H. J. den Hertog Jr. and J. Geevers, Angew. Chem. Suppl., (1982) 1100.

13 J. W. H. M. Uiterwijk, S. Harkema, J. Geevers and D. N. Reinhoudt, J. Chem. Soc., Chem. Commun., (1982) 200.

14 J. A. A. de Boer, D. N. Reinhoudt, S. Harkema, G. J. van Hummel and F. de Jong, J. Am. Chem. Soc., 104 (1982) 4073.

15 J. A. A. de Boer, D. N. Reinhoudt, J. W. H. M. Uiterwijk and S. Harkema, J. Chem. Soc., Chem. Commun., (1982) 194.

16 J. A. A. de Boer, J. W. H. M. Uiterwijk, J. Geevers, S. Harkema and D. N. Reinhoudt, J. Org. Chem., 48 (1983) 4821.

17 F. Vögtle and E. Weber, in S. Patai (Ed.), The Chemistry of functional groups, Suppl. E, Wiley and Sons, Chichester, 1980, p. 59.

$18 \mathrm{H}$. Ackermann and G. Schwarzenbach, Helv. Chim. Acta, 35 (1952) 485.

19 A. Ringbom and L. Eriksson, Acta Chem. Scand., 7 (1953) 1105.

20 D. D. DeFord and D. N. Hume, J. Am. Chem. Soc., 73 (1951) 5321.

21 D. N. Hume, D. D. DeFord and G. B. C. Cave, J. Am. Chem. Soc., 73 (1951) 5323.

22 F. Gaizer, Coord. Chem. Rev., 27 (1979) 195.

23 F. J. C. Rossotti, H. S. Rossotti and R. J. Whewell, J. Inorg. Nucl. Chem., 33 (1971) 2051.

24 M. Tkalcec, B. S. Grabaric, I. Filipovic and I. Piljac, Anal. Chim. Acta, 143 (1982) 255.

25 M. Tkalcec, B. S. Grabaric and I. Filipovic, Anal, Chim. Acta, 122 (1980) 395.

26 D. L. McMasters and W. B. Schaap, Proc. Indiana Acad. Sci., 67 (1957) 111.

27 K. Momoki, H. Sato and H. Ogawa, Anal. Chem., 39 (1967) 1072.

28 I. Piljac, B. S. Grabaric and I. Filipovic, J. Electroanal. Chem. Interfacial Electrochem., 42 (1973) 433.

29 L. Meites, Talanta, 22 (1975) 733.

30 D. J. Leggett, Talanta, 27 (1980) 787.

31 D J. Leggett and W. A. E. McBryde, Anal. Chem., 26 (1975) 1065

32 I. G. Sayce, Talanta, 15 (1968) 1397.

33 H. S. Gold and M. R. Rice, Talanta, 29 (1980) 637.

34 M. Bos, Anal. Chim. Acta, 81 (1976) 21.

35 R. M. Izatt, R. E. Terry, B. L. Haymore, L. D. Hansen, N. K. Dalley, A. G. Avoudet and J. J. Christensen, J. Am. Chem. Soc., 98 (1976) 7620.

36 H. K. Frensdorff, J. Am. Chem. Soc., 93 (1971) 600. 